Telegraphische Depesche des Herrn Professors Bruhns an den Herausgeber.

Tempel beohachtete Comelchen 3. November, $7^{\mathrm{h}} 30^{\mathrm{m}} . \alpha=279^{\circ} 28^{\prime}, \quad$ P. D. $=99^{\mathrm{n}} 14^{\prime}$; vorgestern $6^{\mathrm{h}} 34^{\mathrm{m}} . \quad \alpha=279^{\mathrm{n}} 33^{\prime}$, P. D. $=100^{\circ} 13^{\prime}$. Hier gestern $6^{\mathrm{h}} 24^{\mathrm{m}} . \alpha=279^{\circ} 39^{\prime}$, P. D. $=101^{\circ} 12^{\prime}$. 1871 November 6 .

\title{
Beobachtung des Tempel'schen Cometen.
}

Ich beobachtete mit Dr. Bïrgen hier

1871 Nov. 5, $\underbrace{\text { Mittl. Zt. Leipzig. }}_{6^{\mathrm{h}} 24^{\mathrm{m}} 26^{\mathrm{s}}} \underbrace{A R}_{18^{\mathrm{h}} 38^{\mathrm{m}} 34^{\mathrm{s}} 66} \underbrace{\text { Decl }}_{-11^{\prime \prime} 11^{\prime} 50^{\prime \prime} 9}$ und fand den Cometen schwach, heträchtlich länger in Parallel als im Declinatinnskreise; dir Durchmesser schienen $2^{\prime}$ und $1^{\prime}$ zus sein.

$$
\text { Leipzig, } 1871 \text { Nov. } 6 .
$$

\section{Schreiben des Herrı Dr. Winnecke an den Herausgeber.}

Vom neuen Tempel'schen Cometen habe ich, nach + Vergleichungen mit Lal. 34745, gestern folgenden Ort bestimnt:

$$
\text { of }-*
$$

1871 Nov. $57^{\mathrm{h}} 10^{\mathrm{m}} 43^{\mathrm{s}}$ mittl.Zt. Karlsruhe. $\alpha=+0^{\mathrm{\prime n}} 42^{\mathrm{s}} 04, \delta=+20^{\prime} 31^{\prime \prime} . \quad \alpha \sigma^{\prime}=18^{\mathrm{h}} 38^{\mathrm{m}} 36^{\mathrm{s}} 03, \quad \delta \&^{\prime}=-11^{\circ} 14^{\prime} 28^{\prime \prime}$.

Der Comet ist rund, wenig zur Mitte verdichtet und hat 2 '5 im Durchmesser.

Mit Bezug auf meine Mittheilung Astr. Nachr. 1863 erwähtıe ich, dass es nir heute früh von $17^{\mathrm{h}} 0^{\mathrm{m}}-17^{\mathrm{h}} 15^{\mathrm{m}}$ gelungen ist, dic volle Venusscheibe mit 75 f. Vergr. mcines Hertel'schén Fernohrs unzweifelhaft zu seben. Später kamen Cirri, durch welche keine Spur der gran leuchtenden Naclstseite der Venus zu erblicken war. Höchst anffallend er- scheint mird er Umstand, dass der aussere Rand der grauvioletten Scheibe entschieden heller war.

Als Curiosum erwähne ich, dass der Mond heute den periodischen Cometen von Tuttle bedeckt. Zufolge einer Ephemeride, welche ich der Freundlichkeit von Herrn Hind verdanke, wird die geocentrische Conjunction in AR Nov. $6,6^{\mathrm{h}} 5$ Greew. Statt finden; der Comet steht dann 12' nördlich vom Mondcentrum. Karlsruhe, 1871 Nov. 6.
A. Winnecke.

\section{Beobachtung des Tempel'schen Cometen.}

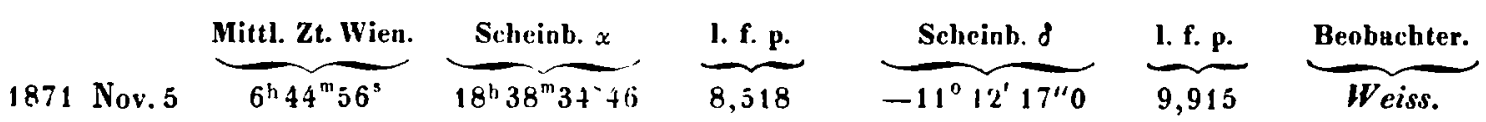

Rundlicher schwacher Nebel von 2-3' Durchmesser, gegen das Centrum mässig verdichtet, ohne deutlichen Kern.

Herr Tempel hat nachträglich seine erste Position berichtigt und eine zweite Beobachtung mitgetheilt, wie folgt:

1871 Nov. $3,7^{\mathrm{h}} 30^{\mathrm{m}}$ mittlere Nailänder Zeit. $\alpha=18^{\mathrm{h}} 37^{\mathrm{m}} 9, \quad \delta=-9^{\circ} 14^{\mathrm{\prime}}$

$$
=4634=:=\quad==38,2= \pm=-1013
$$

Wie n, 1871 November 6.

C. v. Litlrow.

\section{Beobachtung des Tempel'schen Cometen.}

Die Nachricht von der Eutdeckung eines newen Coneten durch Hern Tempel erhielt ich am Abend des 4. November. In Folge eines Fehlers im Telegramm (es stand $: 78^{\prime \prime} A R$ statt $278^{\prime \prime}$ ) wollte nir die Auffindung des Objects an diesem Ahend nicht gelingen. Am 5. November erhich iv: durch gütige Vermittelung der hiesigen Telegraphen-Dircetion die richtige Position. doch war die Nacht his gegen 10 I'? Ir triibe. Erst gestern gelang es mir, den Cometen hei heiterer Luft aufutinden und wie folgt zu heobachten:

1871 Mittl. Hamb. Zt. Scheinb. Ak

Scheinb. Ak

Scheinl. Decl.

Nov. 6 $6^{\mathrm{h}} 45^{\mathrm{m}} 23^{\mathrm{s}} \quad 18^{\mathrm{l}}: 38^{\mathrm{m}} 56^{\mathrm{s}} 99$
Herr Pechiile erhielt folgende Position, hei tieferem Stande des Objects :

$$
\frac{1871}{\text { Nov. } 6} \underbrace{\text { Mittl. Hawb. Zt. }}_{\begin{array}{c}
7^{\prime \prime} 21^{\mathrm{m}} 13^{\mathrm{s}} \\
20 \quad 6
\end{array}} \underbrace{\text { Scheinb. AR }}_{18^{\mathrm{h}} 38^{\mathrm{m}} 59^{\mathrm{s}} 42} \underbrace{\text { Scheinb. Decl. }}_{-12^{\circ} 14^{\prime} 10^{\prime \prime} 8}
$$

Vergleichstern für 1871,0 .

$A R=18^{\prime \prime} 38^{1 n} 39^{\prime \prime} 56, \quad$ Decl. $=-12^{\prime \prime} 13^{\prime} 22^{\prime \prime} 3$. Weisse 945.

Der Comet ist gut condensirt, etwa eine Minute im Durchmesser, und leidlich bell.

H a mburg, 1871 November 7. George Rümker. 